\title{
In-vitro and in-silico evaluation of the anti-chikungunya potential of Psidium guajava leaf extract and their synthesized silver nanoparticles
}

\author{
Yashika Sharma $^{1}$ - Anubhuti Kawatra ${ }^{1}$. Vikrant Sharma ${ }^{1}$ Divya Dhull ${ }^{1}$. \\ Sulochana Kaushik ${ }^{2} \cdot$ Jaya Parkash Yadav $^{2} \cdot$ Samander Kaushik $^{1}$ (D)
}

Received: 23 January 2021 / Accepted: 22 March 2021/Published online: 11 April 2021

(C) Indian Virological Society 2021

\begin{abstract}
Chikungunya is a notorious viral infection, which affects a large segment of world populations in absence of vaccines and antivirals. The current study evaluates of anti-chikungunya activities of Psidium guajava leaves extract and their green synthesized silver nanoparticles. Green synthesized nanoparticles were well characterized for their size and stability by dynamic light scattering (DLS), zeta potential, scanning electron microscopy (SEM) and their functional groups were analyzed by FTIR. Maximum non-toxic doses (MNTD) of extracts and nanoparticles were analysed by using Vero cell-lines. Antichikungunya activities of extracts and nano-particles were determined on Vero cells and their effects on cell viability were measured by MTT assay. The $P$. guajava nano-particles and extracts revealed the anti-chikungunya activities in the Vero cell. The cells viability was increased by $40 \%$ and $60 \%$ as compared to the virus control, when these cells were treated with MNTD of $P$. guajava nano-particles and extracts, respectively. To know the reason for antiviral activity, molecular docking of phytochemicals was done against a replication essential cysteine protease (nsP2) of Chikungunya. It was found that phytochemicals; Longifollen and Quercetin showed the minimum binding energy with nsP2. P. guajava extracts can be exploited to develop
\end{abstract}

Supplementary Information The online version contains supplementary material available at https://doi.org/10.1007/s13337021-00685-4.

Samander Kaushik

samanderkaushik@gmail.com

1 Centre for Biotechnology, Maharshi Dayanand University, Rohtak, (Hr), India

2 Department of Genetics, Maharshi Dayanand University, Rohtak, (Hr), India an effective anti-chikungunya agent. In the absence of CHIKV vaccines and antivirals, $P$. guajava may be used to develop rapid, responsive, specific, and cost-effective antichikungunya agents.

Keywords Chikungunya virus · Psidium guajava . Antiviral $\cdot$ Nanotechnology $\cdot$ Cytotoxicity $\cdot$ Molecular docking

\section{Introduction}

Chikungunya is a mosquito-borne viral infection. Chikungunya virus (CHIKV) is an envelope, a single-stranded RNA virus that belongs to the genus alphavirus of the Togaviridae family. CHIK is characterized by fever, arthralgia, peripheral joint pains, and in severe cases encephalitis. CHIKV is generally is a silent virus but a recent mutation in the $\mathrm{E} 1$ gene at $\mathrm{A} 226 \mathrm{~V}$ position has enhanced its vector spectrum. The CHIKV re-emerged around 2000-2008 when an east African strain spread around the Republic of Congo and various other neighbouring islands [4]. The mutant strain of CHIKV is responsible for many recent outbreaks worldwide. More than 1.3 million cases were noted from India in 2006 [2]. In 2016, India and its neighbour countries faced another episode of the Chikungunya outbreak [7]. Due to the absence of specific treatment and high impact of Chikungunya, scientists suggest the use of monoclonal antibodies, nucleic acids modifier, designer molecules, and secondary photochemical [20]. Ayurveda and Siddha system indicate that herbal compounds with numerous compositions can be very helpful. The medicinal plants are the primary source of multiple pharmaceutical agents and help to control various infectious or non-infectious diseases. Herbal 
compounds are relatively safer and economical source than the synthetic therapeutic agents. Psidium guajava (Guava) is a well-known fruit plant with medicinal value in its various parts. As barks, leaves, and fruit of $P$. guajava have shown promising antiviral effects against the Influenza H5N1, H1N1, Dengue virus, Herpes simplex virus, Hepatitis B virus, Rotavirus [26]. The present study is focused on the anti-chikungunya potential of P. guajava leaf extract and their synthesized silver nanoparticles. We have compared anti-chikungunya activities of $P$. guajava extracts and their nanoparticles in the animal cell culture model and their interventions studied by the in-silico approach also.

\section{Materials and methods}

\section{Collection of plant material and preparation of aqueous extracts}

Fresh and healthy leaves of $P$. guajava were collected in March 2019 from the guava plant of the Herbal Garden of M. D. University, Rohtak (Haryana), India. The leaves were dried in shade at room temperature and grounded into a coarse powder. The $10 \%$ aquatic extract of $P$. guajava leaves powder was prepared by overnight incubation in a shaker incubator at room temperature. The extract obtained was filtered and lyophilized before storage.

\section{Preparation of silver nanoparticles (AgNPs)}

Green AgNPs of $P$. guajava were prepared by adding various concentration of the aqueous leaves extract in $1 \mathrm{mM}$ silver nitrate solution. The mixture was kept in a boiling water bath with continuous stirring for 15-20 min. The colour change was noted after $24 \mathrm{~h}$ incubation.

\section{Characterization of crude aqueous extracts and synthesized silver nanoparticles}

The spectrophotometric analysis for functional groups of extracts and nanoparticles was done by FTIR. The percentage transmission spectrum of $P$. guajava extracts and nanoparticles was obtained in the range of $4000-500 \mathrm{~cm}^{-1}$. The synthesized AgNPs were further characterized by UVVIS Spectrophotometer (UV-2450 Shimadzu Corp., Japan) with the absorption spectra in the range of 300-600 nm and distilled water was used reference blank. The surface morphology of synthesized silver nanoparticles was accessed with the help of scanning electron microscopy (Hitachi Model-E1010, Japan). DLS and zeta potential analysis for approximate size and charge of $P$. guajava
AgNPs was done with DLS-Malvern Zetasizer NanoZS (Malvern Panalytical, UK).

\section{Vero cells and CHIKV culture conditions}

Vero cells are recommended for CHIKV were maintained at $28{ }^{\circ} \mathrm{C}$ under a humidified $5 \% \mathrm{CO}_{2}$ incubator in Dulbecco's minimal essential medium (DMEM) supplemented with $10 \%$ fetal bovine serum (FBS), two antibiotics; penicillin and streptomycin. Viral growth media has a similar composition with $2 \%$ fetal bovine serum only.

\section{Cytotoxicity assay and median tissue culture infective dose (TCID $\left._{50}\right)$ of $\mathrm{CHIKV}$}

The cytotoxicity assays of extracts and silver nanoparticles were done with the help of adding a serial dilution of their stock solutions $(2 \mathrm{mg} / \mathrm{ml}$ of DMEM) in the Vero cell line. The $80-90 \%$ confluent wells of 96-well plate were treated with a two-fold serial dilution of stock solution of $P$. guajava extracts and silver nanoparticles in triplicates. The plates were incubated and microscopically observed for cytotoxicity daily. For assessing the remaining proportion of viable cells, MTT assay was performed. Indian Ocean lineage (IOL) of standard strain of CHIKV was taken for the present study. The TCID 50 of CHIKV for virus quantification was done based on their cytopathic effect (CPE) in Vero cells as per Reed and Munch methods.

\section{Antiviral activity assay}

The confluent monolayers were pre-treated with MNTDs of extracts and silver nanoparticles. After proper incubation, the medium was removed and challenged with $\operatorname{TCID}_{50}$ doses of CHIKV. Inoculated cells were incubated at $28{ }^{\circ} \mathrm{C}$ in a $5 \% \mathrm{CO}_{2}$ incubator for a week and viral effects were evolved by CPE and MTT assays.

\section{Docking analysis}

The molecular docking target for CHIKV, nsP2 cysteine protease (PDB ID: 3TRK) was retrieved from PDB. 3D structure of the following ligands were retrieved from PubChem, Resveratrol (PubChem CID: 445154); Quercetin (PubChem CID: 5280343); Guaijaverin (PubChem CID: 5481224); beta-Caryophyllene (PubChem CID: 5281515); Longifollen (PubChem CID: 1796220); beta-Bisabolene (PubChem CID: 10104370); Limonene (PubChem CID: 22311). Autodock 4.2.6 was used for docking analysis. Removal of Crystallographic water and addition of charges was done with Autodock to generate a pdbqt file of the target. Similarly, all the ligands were also processed and saved to generate respective pdbqt files. Genetic algorithms 
were used for searching and target was kept rigid while flexible ligands were docked to its active sites.

\section{Results and discussion}

\section{Standardization condition for preparation of silver nanoparticles}

A $5 \mathrm{ml}$ aqueous leaves extract of $P$. guajava was added to $95 \mathrm{ml}$ of $1 \mathrm{mM}$ silver nitrate solution drop-wise with constant stirring till the desired colour developed. The mixture was kept in a boiling water bath for $15 \mathrm{~min}$. The change in colour from pale green to dark brown indicates the synthesis of nanoparticles (Supplementary Fig. S1).

\section{Characterization of $P$. guajava extracts}

FTIR analysis of $P$. guajava extracts showed the presence of a distinct broad peak at 3262 that corresponds to the presence of alcoholic and phenolic functional groups in addition to this, peaks at 2933, 2099 and 930 reflect the presence of alkane alkyne and alkene respectively. The presence of the aromatic group was reflected by 1980, 1605 peaks shown in Supplementary Fig. S2a. Similarly in nanoparticles, the FTIR spectrum reveals the presence of alcohol and phenols (3216, 1335), alkane (2917; 1514), alkyne $(2165,2128,2040)$ alkenes $(816)$, aromatic groups $(1707 ; 1600)$ in Supplementary Fig. S2b.

\section{Synthesis and characterization of silver nanoparticles}

The preliminary confirmation of the synthesis of nanoparticles was done by a change in color from pale green to light brown (Supplementary Fig. S1). The spectrum scans yielded a sharp peak at $420 \mathrm{~nm}$ that signifies the presence of Nano-silvers in a colloidal solution (Fig. 1a). The scanning electron microscope predicts the average size of AgNP in the range of $75-99 \mathrm{~nm}$ as in Fig. 1b. Similarly, the average size of nanoparticles by DLS in the colloidal system was $78.16 \mathrm{~nm}$ shown in Fig. 1c Zeta potential gives an estimated potential difference in negative polarity that signifies its stability at room temperature. The average Zeta potential of $P$. guajava leaf silver nanoparticles was $-18.2 \mathrm{mV}$ in Fig. 1d. The size and stability of nanoparticles were checked by DLS and Zeta potential before use.

\section{Cytotoxicity assay and median tissue culture infective dose (TCID50) of CHIKV}

The cytotoxicity dose of both extracts and silver nanoparticles were found the same $15 \mu \mathrm{g} / \mathrm{ml}$. The cytotoxicity was determined based on cell viability percentage calculated by MTT assays.

\section{In-vitro antiviral assay}

Antiviral activity of $P$. guajava extracts was analyzed in terms of reduction in the cytopathic effect due to CHIKV. The positive control (virus + cells) has $24.03 \%$ viability, plant extract (Plant extract + virus + cells) $84.21 \%$ viability, plant extract nanoparticles (Plant extract nanoparticles + virus + cells) $64.40 \%$ viability, while cell control (Cell only) $100 \%$ cells survive. More cells survive in aqueous extracts and silver nanoparticles of $P$. guajava indicate the efficacy of plants (Fig. 2).

\section{Molecular docking}

The selected target showed promising interactions with previously reported $P$. gujava phytochemicals. Out of all the complexes Quercetin, Beta-Caryophyllene, and Longifollen showed minimum binding energy viz, -6.66 , -6.27 and -8.26 respectively (Fig. 3a). While Resveratrol $(-6.18)$, Guaijaverin $(-5.89)$, Limonene $(-5.82)$ and Beta-bisabolene ( -5.44$)$ showed high binding energy (Fig. 3b). Various types of amino acid residues involved in the interaction, binding energies are mentioned in Supplementary Table S1.

Recent trends on vector born infectious diseases such as Dengue, CHIK, Zika, Nipah and COVID-19 have raised a very serious health concern [9, 23, 23, 24, 24, 25]. In such scenarios, ethnomedicine is gaining interest because of its safety and broad-spectrum activity over synthetic drugs. A renowned plant family of $P$. guajava, Myrtaceae has several plants with therapeutic potential. Methanolic extracts of $C$. nutans, $C$. sinaica are effective against HSV2 and Influenza H5N1 strain respectively [6, 27]. A large variety of traditional medicinal herbs and plants have been reported to exhibit antiviral activities against CHIKV [10], HCV, Dengue [8, 11, 12], HIV [3], Influenza [17] and HSV viruses [1]. Even $P$. guajava has antibacterial, antifungal, anti-inflammatory potential [5, 22]. Nano-silver has the capacity to enhanced antiviral activity in-vitro [23, 24]. There are various ways to synthesized silver nanoparticles [14-16]. In the present study synthesized silver nanoparticles were characterized followed by the analysis of their anti-CHIKV potential. The magnitude of zeta potential gives an estimate of particle stability in the colloidal system and its cellular uptake. Nanoparticles depict average zeta potential of $-18.2 \mathrm{mV}$ that signifies their stability by electrostatic repulsion which will prevent the aggregation and agglomeration. Particle size estimation shows a homogeneous suspension of size $78.16 \mathrm{~d}$.nm with a poly disparity index of 0.45 . The following results signify that 

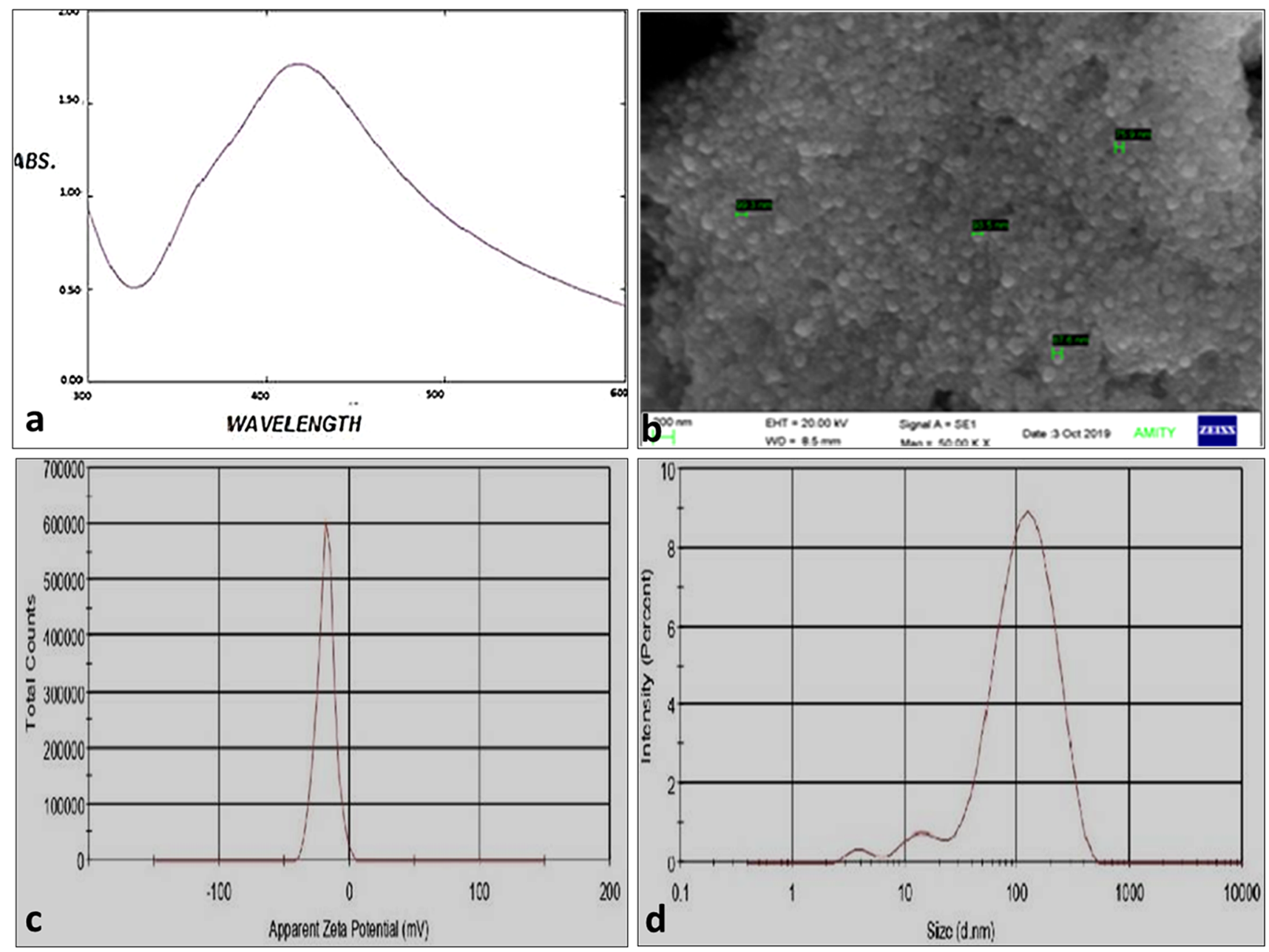

Fig. 1 Characterization of synthesized silver nanoparticles by a UV-VIS spectrophotometry, b scanning electron microscopy, c dynamic light scattering (DLS), d zeta potential

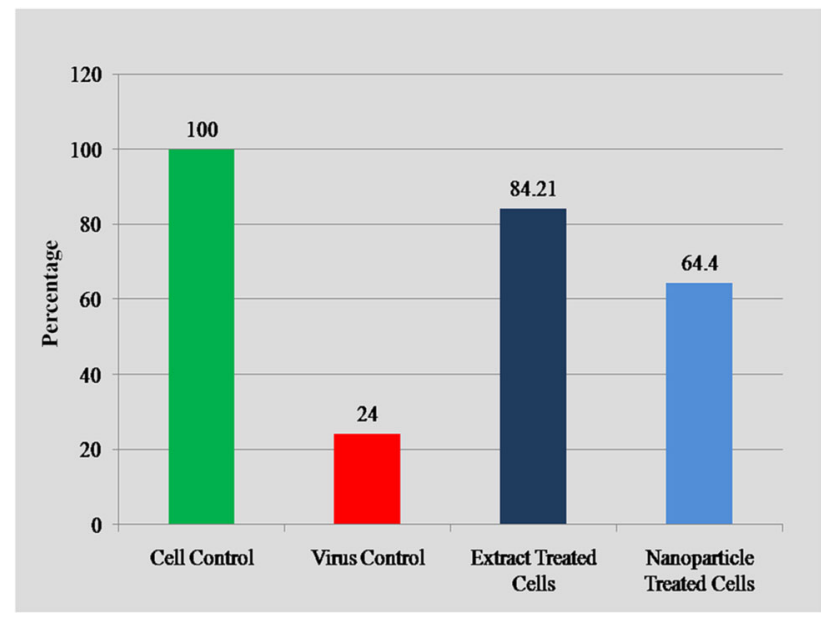

Fig. 2 Effect of $P$. guajava extracts and its silver nanoparticles on Vero cell viability with respect to CHIKV control

the synthesized AgNPs are monodispersed and stable in a colloidal solution. FTIR transmittance analysis of both extracts and silver nanoparticles shows the presence of sharp distinct peaks. The wave numbers of the peaks correspond to the presence of specific functional groups. Aqueous extracts and silver nanoparticles show peaks around 3262 and 3216 respectively that correspond to the presence of the alcoholic or phenolic functional group. Similarly peaks at 1605, 1980 and 1707, 1600 depict the presence of aromatic compounds. Both extracts and silver nanoparticles show the presence of alkanes and alkenes. Study groups on leaf extracts of $P$. guajava suggest an abundance of cyclic sesquiterpene "Caryophyllene", monoterpene "Limonene", cyclohexane "Bisabolene" "Longifollen" and polyphenol "Quercetin" [13, 18, 19]. An interesting study on a quercetin pyranoside "Guijaverin" isolated from leaf extract of $P$. guajava depicts their promising anti-plaque activity [21]. Mentioned constituents also depict similar peaks at their standard FTIR spectra (available at PubChem). In addition to this, a replication essential cysteine protease which also behaves as helicase was used as a target for docking probable $P$. 


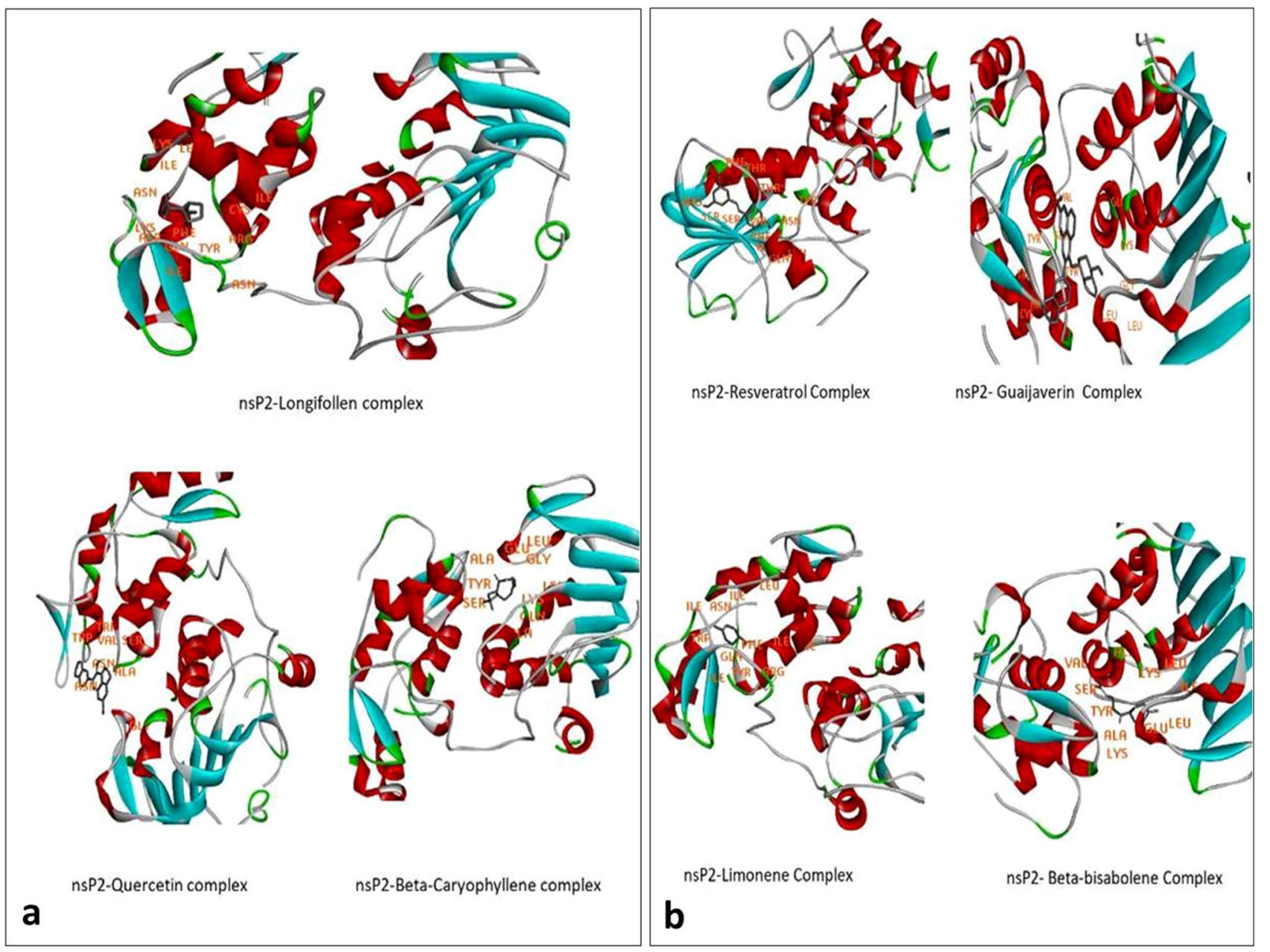

Fig. 3 Docked structures of $P$. guajva phytochemicals a Longifollen, Quercetin and Beta-Caryophylleneand, b resveratrol, Guaijaverin, Limonene and Beta-bisabolene in nsP2 of CHIKV

guajava leaf metabolites. Upon docking these plant metabolites nsP2 of CHIKV, Longifollen showed minimum binding energy that signifies its stable interaction. On the other hand, Quercetin and Caryophyllene also showed promising binding with the cysteine protease. Least stable interactions with the cysteine protease were showed by Bisabolene and Limonene. The study indicates a possible use of plant-based medicines to cure the Chikungunya disease burden. Apart from CHIKV other prevalent viral diseases such as Dengue, herpes, and influenza are also anticipated to be tackled by ethnobotanical sources.

In-vitro and in-silico evaluation of the anti-chikungunya potential of $P$. guajava leaf extract and their synthesized silver nanoparticles study results reveal the importance of $P$. guajava to combat with the chikungunya virus. Increasing cell viability during antiviral assay indicates that $P$. guajava extract and its nanoparticles reduce/stop the replication of the chikungunya virus in cell-line and insilico study explains the inhibition of viral replication. In absence of vaccines and antivirals medicinal plants $(P$. guajava) could be a source for the exploitation of alternative treatment options for the chikungunya virus.

Funding This research did not receive any specific grant from any funding agencies.

\section{References}

1. Álvarez ÁL, Habtemariam S, Parra F. Inhibitory effects of lupene-derived pentacyclic triterpenoids from Bursera simaruba on HSV-1 and HSV-2 in vitro replication. Nat Prod Res. 2015;29:2322-7. https://doi.org/10.1080/14786419.2015. 1007456.

2. Arankalle VA, Shrivastava S, Cherian S, Gunjikar RS, Walimbe AM, Jadhav SM, Sudeep AB, Mishra AC. Genetic divergence of Chikungunya viruses in India (1963-2006) with special reference to the 2005-2006 explosive epidemics. J Gen Virol. 2007;88:1967-76. https://doi.org/10.1099/vir.0.82714-0.

3. Benso B, Rosalen PL, Pasetto S, Marquezin MC, Freitas-Blanco $\mathrm{V}$, Murata RM. Malva sylvestris derivatives as inhibitors of HIV- 
1 BaL infection. Nat Prod Res. 2019;25:1-6. https://doi.org/10. 1080/14786419.2019.1619720.

4. Burt FJ, Rolph MS, Rulli NE, Mahalingam S, Heise MT. Chikungunya: a re-emerging virus. Lancet. 2012;379:662-71.

5. Deguchi Y, Miyazaki K. Anti-hyperglycemic and anti-hyperlipidemic effects of guava leaf extract. Nutr Metab. 2010;7:9. https://doi.org/10.1186/1743-7075-7-9.

6. Ibrahim AK, Youssef AI, Arafa AS, Ahmed SA. Anti-H5N1 virus flavonoids from Capparis sinaica Veill. Nat Prod Res. 2013;27:2149-53. $\quad$ https://doi.org/10.1080/14786419.2013. 790027.

7. Kaur N, Jain J, Kumar A, Narang M, Zakaria MK, Marcello A, Kumar D, Gaind R, Sunil S. Chikungunya outbreak in Delhi, India, 2016: report on co-infection status and comorbid conditions in patients. New Microbes New Infect. 2017;20:39-42. https://doi.org/10.1016/j.nmni.2017.07.007.

8. Kaushik S, Dar L, Kaushik S, Yadav JP. Identification and characterization of new potent inhibitors of dengue virus NS5 proteinase from Andrographis paniculata supercritical extracts on in animal cell culture and in silico approaches. J Ethnopharmacol. 2021;267:113541. https://doi.org/10.1016/j.jep.2020. 113541.

9. Kaushik S, Jangra G, Kundu V, Yadav JP, Kaushik S. Anti-viral activity of Zingiber officinale (Ginger) ingredients against the Chikungunya virus. Virus Dis. 2020;31(3):270-6. https://doi.org/ 10.1007/s13337-020-00584-0.

10. Kaushik S, Kaushik S, Kumar R, Dar L, Yadav JP. In-vitro and in silico activity of Cyamopsis tetragonoloba (Gaur) L. supercritical extract against the dengue-2 virus. Virus Dis. 2020;31(4):470-8. https://doi.org/10.1007/s13337-020-00624-9.

11. Kaushik S, Kaushik S, Sharma V, Yadav JP. Antiviral and therapeutic uses of medicinal plants and their derivatives against dengue viruses. Pharmacog Rev. 2018;12:177-85. https://doi.org/ 10.4103/phrev.phrev_2_18.

12. Kaushik S, Kaushik S, Sharma Y, Kumar R, Yadav JP. The Indian perspective of COVID-19 outbreak. VirusDis. 2020;31(2):146-53. https://doi.org/10.1007/s13337-020-00587-x.

13. Li J, Chen F, Luo J. GC-MS analysis of essential oil from the leaves of P. guajava. J Chin Med Mat. 1999;22:78-80.

14. Litvin VA, Minaev BF, Baryshnikov GV. Experimental and theoretical study of the mechanism formation of silver nanoclusters in the reduction reaction of $\mathrm{Ag}^{+}$ions by alizarin solution. Colloid Interface Sci Commun. 2019;29:47-54. https://doi. org/10.1016/j.colcom.2019.02.001.

15. Litvin VA, Minaev BF, Galagan RL, Baryshnikov GV, Ågren H. Growth of silver nanoparticles using polythiocyanatohydroquinone in aqueous solution. Acta Chim Slov. 2019;66:427-34. https://doi.org/10.17344/acsi.2019.4890.

16. Mishra RC, Kumari R, Yadav JP. Comparative study of antidandruff Efficacy of Punica granatum peel and its biosynthesized silver nanoparticles. J Bionanosci. 2018;12:508-14. https://doi. org/10.1166/jbns.2018.1562.

17. Moradi MT, Karimi A, Rafieian-Kopaei M, Fotouhi F. In vitro antiviral effects of Peganum harmala seed extract and its total alkaloids against Influenza virus. Microb Pathog. 2017;110:42-9. https://doi.org/10.1016/j.micpath.2017.06.014.

18. Naseer S, Hussain S, Naeem N, Pervaiz M, Rahman M. The phytochemistry and medicinal value of Psidium guajava (guava). Clin Phytosci. 2018;4:1-8. https://doi.org/10.1186/s40816-0180093-8.

19. Ogunwande IA, Olawore NO, Adeleke KA, Ekundayo O, Koenig WA. Chemical composition of the leaf volatile oil of Psidium guajava L. growing in Nigeria. Flavour Frag J. 2003;18:136-8. https://doi.org/10.1002/ffj.1175.

20. Powers AM. Vaccine and therapeutic options to control chikungunya virus. Clin Microbiol Rev. 2018;31:e00104-e116. https:// doi.org/10.1128/CMR.00104-16.

21. Prabu GR, Gnanamani A, Sadulla S. Guaijaverin-a plant flavonoid as a potential antiplaque agent against Streptococcus mutants. J Appl Microbiol. 2006;101:487-95. https://doi.org/10. 1111/j.1365-2672.2006.02912.x.

22. Sanda KA, Grema HA, Geidam YA, Bukar-Kolo YM. Pharmacological aspects of Psidium guajava: an update. Int J Pharmacol. 2011;7:316-24. https://doi.org/10.3923/ijp.2011.316.324.

23. Sharma V, Kaushik S, Kumar R, Yadav JP, Kaushik S. Emerging trends of Nipah virus: a review. Rev Med Virol. 2019;29:e2010. https://doi.org/10.1002/rmv.2010.

24. Sharma V, Kaushik S, Pandit P, Dhull D, Yadav JP, Kaushik S. Green synthesis of silver nanoparticles from medicinal plants and evaluation of their antiviral potential against chikungunya virus. Appl Microbiol Biotechnol. 2019;103:881-91.

25. Sharma V, Sharma M, Dhull D, Sharma Y, Kaushik S, Kaushik S. Zika virus: an emerging challenge to public health worldwide. Can J Microbiol. 2020;66:87-98. https://doi.org/10.1139/cjm2019-0331.

26. Trujillo-Correa AI, Quintero-Gil DC, Diaz-Castillo F, Quiñones $\mathrm{W}$, Robledo SM, Martinez-Gutierrez M. In vitro and in silico anti-dengue activity of compounds obtained from Psidium guajava through bio-prospecting. BMC Compl Altern Med. 2019;19:298. https://doi.org/10.1186/s12906-019-2695-1.

27. Vachirayonstien T, Promkhatkaew D, Bunjob M, Chueyprom A, Chavalittumrong P, Sawanpanyalert P. Molecular evaluation of the extracellular activity of medicinal herb Clinacanthus nutans against Herpes Simplex Virus type-2. Nat Prod Res. 2010;24:236-45. https://doi.org/10.1080/14786410802393548.

Publisher's Note Springer Nature remains neutral with regard to jurisdictional claims in published maps and institutional affiliations. 